\title{
Oncologic, Perioperative Outcomes of Female Radical Cystectomy: Results from a Multicenter Study in Korea
}

\section{Ji Sung Shim, MD, PhD' \\ Ho Kyung Seo, MD, PhD² \\ Ja Hyeon Ku, MD, PhD 3 \\ Byong Chang Jeong, MD, $\mathrm{PhD}^{4}$ \\ Bumsik Hong, MD, PhD ${ }^{5}$ \\ Seok Ho Kang, MD, $P h D^{1}$ \\ UCART (Urothelial Cancer-Advanced \\ Research and Treatment Group in Korea) \\ Group}

${ }^{1}$ Department of Urology, Korea University School of Medicine, Seoul, ${ }^{2}$ Department of Urology, National Cancer Center, Goyang, ${ }^{3}$ Department of Urology, Seoul National University School of Medicine, Seoul, ${ }^{4}$ Department of Urology, Sungkyunkwan University School of Medicine, Seoul, ${ }^{5}$ Department of Urology, Asan Medical Center, University of Ulsan,

College of Medicine, Seoul, Korea
Correspondence: Seok Ho Kang, MD, PhD Department of Urology, Korea University

College of Medicine, 73 Inchon-ro,

Seongbuk-gu, Seoul 02841, Korea

Tel: 82-2-920-5530

Fax: 82-2-928-7864

E-mail: mdksh@korea.ac.kr

Co-correspondence: Bumsik Hong, MD, PhD Department of Urology, Asan Medical Center, 88 Olympic-ro 43-gil, Songpa-gu,

Seoul 05505, Korea

Tel: 82-2-720-1684

Fax: 82-2-720-3728

E-mail: bshong@amc.seoul.kr

Received September 16, 2018

Accepted October 29, 2018

Published Online October 30, 2018

\section{Purpose}

The lower incidence of bladder cancer among women has led to a lack of information on female radical cystectomy $(\mathrm{RC})$. This study aimed to analyze the characteristics related with female RC in a cohort from multiple academic institutions.

\section{Materials and Methods}

This was a retrospective review of 384 female patients who underwent RC for bladder cancer. Epidemiologic, perioperative variables including urologic referral period with consequent pathologic stage distributions were assessed. The changes in surgical techniques over time were illustrated. Also, we evaluated recurrence-free survival (RFS) at 2 and 5 years and overall survival (OS) at 5 years with stage-specific analyses using the Kaplan-Meier method.

\section{Results}

The mean follow-up time was 35 months (interquartile rage [IQR], 9 to 55). The average time to urologic referral with initial symptoms was 5.5 (IQR, 1 to 6 ) months and over $20 \%$ of patients visited clinics after 6 months. In subsequent stage distributions according to referral period, $\mathrm{T} 2$ or higher stage distributions were abruptly increased after 1 year. Overall 2-year/5-year RFS rates were $0.72 / 0.57$ and 5 -year OS was 0.61 . Notable surgical descriptions were as follows: $91 \%$ of patients underwent open RC; $80 \%$ of patients underwent an ileal conduit; and $83 \%$ of patients received anterior exenteration. However, the proportions of robotic surgery, orthotopic neobladder and organ sparing cystectomy have increased recently.

\section{Conclusion}

We identified the general characteristics and changes in pattern of female RC. Our results also suggest that women are susceptible to delays in referral to an urologist and are at greater risk for worse prognosis.
Key words

Cystectomy, Female, Urinary bladder neoplasms 


\section{Introduction}

Women are two to four times less likely to develop bladder cancer than men [1]. Although anatomy or surgical technique differs between sexes in performing radical cystectomy (RC), the lower prevalence of female bladder cancer has inevitably led to a lack of information. The absolute number of women undergoing $\mathrm{RC}$ is increasing worldwide recently [2], making the overall information on the surgery more necessary.

There were some issues related to the female $\mathrm{RC}$. The first is about the specific surgical technique with changes in procedure. For example, ileal conduits have been widely used for urinary diversion, because women were initially excluded from orthotopic neobladder (ONB) reconstruction due to concerns about urethral recurrence (oncologic aspect) and postoperative urinary incontinence or hypercontinence (functional aspect). However, established indications for ONB and improvements in the understanding of the rhabdosphincter anatomy have led to the increased use of ONB. In addition, the proportion of laparoscopic or robotic surgery has increased with the development of minimally invasive surgery, and the rate of organ sparing surgery has changed which makes the pattern of female cystectomy different from that performed in the past. In this regard, it will be useful to investigate the various surgical methods for performing female $\mathrm{RC}$ and changes over time.

Second, even if clinicians recognize the importance of demographic heterogeneity in the management of patients with bladder cancer, the effects of gender on incidence, staging, prognosis, complications, and survival are controversial $[3,4]$. Previous studies demonstrated impaired outcomes in women and that they are more likely to undergo RC at the advanced tumor stage [3,5]. For this reason, risk factor exposure due to anatomical features, and hormonal differences by sex have been suggested for these differences [6]. Also, delayed urological care of women who present with hematuria was continuously proposed [7].

In our study, we investigated the characteristics related with female RC, to search for perioperative, oncologic outcomes as well as epidemiologic factors, and aspects of surgical technique transition.

\section{Materials and Methods}

\section{Patient deposition and follow-up}

A total of five tertiary referral centers provided data. This study comprised 384 female patients with muscle invasive disease or recurrent Ta, T1, or carcinoma in situ refractory to transurethral resection of bladder tumor who underwent RC and bilateral pelvic lymph node dissection with urinary diversion between 2007 and 2016. All patients had pathologic documentation of bladder cancer and with no evidence of distant metastasis at the time of RC. Patients were followed up postoperatively every 3 to 4 months for the first year, semiannually for the second year and annually thereafter. At regular follow up, disease recurrence was checked which defined as pathologic or radiographic evidence of cancer after cystectomy.

\section{Epidemiologic factors and perioperative variables}

Risk factors exposure history (smoking, chemical exposure to occupation-dye, paint, metal, and petroleum) and other various basic information were recorded. Also, the perioperative outcomes including operation time, estimated blood loss and mean hospital stay were evaluated. The durations from the onset of symptoms (hematuria, lower urinary tract symptoms, flank pain, etc.) to the urologic referral were recorded. Thereafter, pathologic $\mathrm{T}$ category distribution $(\leq \mathrm{T} 1, \mathrm{~T} 2, \mathrm{~T} 3$, and T4) of patients were assessed by referral period (within 1, 3, 6, and 12 months and over 1 year).

\section{Evaluation of oncologic outcome}

We evaluated recurrence-free survival (RFS) at 2 and 5 years with overall survival (OS) at 5 years with stage-specific analyses. Patients who did not experience recurrence were censored at the time of last follow-up for RFS analysis. Disease recurrence was defined as local failure in the operative site, regional lymph nodes, or distant metastasis and cause of death was determined by the treating physician, by chart review corroborated by death certificates. Also, final $\mathrm{T}$ and $\mathrm{N}$ category, margin status and histologic distributions were described.

\section{Changes in surgical technique in female RC during 10 years}

The relative specific changes in surgical proportions and changes over ten years were analyzed as follows: (1) open/ laparoscopic/robotic surgery, (2) type of urinary diversion (ileal conduit/ONB/ continent cutaneous urinary diversion), and (3) anterior exenteration/organ sparing RC.

\section{Surgical technique description: anterior exenteration}

For RC without uterine preservation, identification of the whitish vaginal outer wall is important. A landmark can be made by inserting ringed forceps into the vagina, and a peri- 
toneal incision would be placed in the Douglas pouch just below the vaginal fundus. After ligation of the dorsomedial pedicle, excision of the vaginal wall covering the trigone can be performed without significant blood loss. Considering the location of the tumor, raising the caudal resection of anterior vaginal wall to the cephalad direction than the urethral resection plane may reduce the risk of vesicovaginal fistula [8] which is further reduced when electrocautery is avoided to the tissue borders required for approximation.

\section{Surgical technique description: organ-sparing RC}

Basically, organ-sparing RC could be performed in the absence of invasive cancer in the trigone, dorsal or lateral side wall (unifocal, $\leq \mathrm{cT} 2 \mathrm{~b}$ ). The surgical techniques are slightly different for each surgeon, but based on the following method which has been described for both open [9] and robotic approaches [10]. The infundibulo-pelvic, broad, and round ligaments are preserved and related vessels (including distal vessels, which go to the paravaginal tissue and pelvic plexus) should be identified as they cross close to the ureters. It is important to identify the plane on the outer surface of the vaginal wall after incision of the uterovesical junction. The dorsomedial bladder pedicle would be extensively resected or the plane of anteroventral vagina could be resec- ted for nerve sparing. In addition, for continence preservation for the ONB, dissection in the retropubic space should be aimed at preserving the endopelvic fascia, pubo-urethrovesical attachments, with minimal trauma to the levator muscles and periurethral tissue.

\section{Analysis}

RFS and OS probabilities were estimated using the KaplanMeier method and differences between groups were assessed using the log-rank test. All analyses were performed and illustrated using SPSS ver. 20.0 (IBM Corp., Armonk, NY) and Sigmaplot ver. 13.0 (Systat Software Inc., San Jose, CA). p-values of $<0.05$ were considered statistically significant.

\section{Ethical statement}

This study was approved by the ethics committees and the Institutional Review Boards of each hospital (IRB No. ED10120) that participated in the study, and the requirement for the patients to provide consent was waived.

Table 1. Baseline patient characteristics

\begin{tabular}{|lc|}
\hline Age $(\mathbf{y r})$ & Value (n=384) \\
\hline BMI $\left(\mathbf{k g} / \mathbf{m}^{2}\right)$ & $66 \pm 10$ \\
\hline Time to urological referral (mo) & $23.8 \pm 3.7$ \\
\hline Within 1 mo (\%) & $2(1-6)$ \\
\hline Within 3 mo (\%) & 45.4 \\
\hline Within 6 mo (\%) & 18.9 \\
\hline Within 12 mo (\%) & 15.2 \\
\hline Over 1 year & 13.8 \\
\hline Risk factors exposure & 6.7 \\
\hline None & $357(93.0)$ \\
\hline Smoking & $20(5.2)$ \\
\hline Radiation exposure & $7(1.8)$ \\
\hline Other chemical exposure (metal, paint, petroleum, etc.) & 0 \\
\hline Preoperative chemotherapy & $65(17)$ \\
\hline Follow-up period (mo) & $24(9-51)$ \\
\hline Perioperative outcomes & $410(350-477)$ \\
\hline Operation time (min) & $800(450-1,300)$ \\
\hline EBL (mL) & $19(14-25)$ \\
\hline Hospital stays (day) & \\
\hline
\end{tabular}

Values are presented as mean \pm standard deviation, median (interquartile range), or number (\%). BMI, body mass index; EBL, estimated blood loss. 


\section{Results}

\section{Baseline characteristics and descriptive data on opera- tion}

The mean patient age was 66 years (interquartile range [IQR], 59 to 73) and the median follow-up period was 24 months (IQR, 9 to 51). Neoadjuvant chemotherapy was administered to 65 women $(17 \%)$. In the analysis of perioperative outcomes, the median operation time was 410 minutes (IQR, 350 to 477) and the median length of hospital stay was 19 (IQR, 14 to 25) (Table 1).

Among the initial symptoms, gross hematuria alone or in combination with any other symptoms accounted for $66 \%$ of all cases. This was followed by, 6.5\% for dysuria, $2.3 \%$ for microscopic hematuria, and $16.7 \%$ for other symptoms such as urgency or flank pain (Fig. 1).

\section{Time to urologic referral and differences in pathologic $T$ category according to the period}

The median time to urologic referral was 2 months (IQR, 1 to 6$)$ and $45.4 \%$ of all patients visited clinics within one month while over $20 \%$ of the patients visited the hospital after 6 months from the onset of symptoms (Table 1).

We analyzed the differences in pathologic $\mathrm{T}$ category according to the period for the urologic referral from symptom onset. T2 or lower stage occurred in $67 \%$ of patients who visited clinics within 1 month. Not much difference in T2 or lower stage distribution ( $\leq \mathrm{T} 1,56 \%$; T2, 59\%; and T3, 60\%) in patients who visited within 1 year, T2 or higher proportion increased significantly and was present in $87 \%$ of patients who visited clinics after 1 year (Fig. 2).

\section{Oncologic outcomes}

The overall 2-year /5-year RFS rates were $0.72 / 0.57$ and 5 -year OS was 0.61 for all patients. The results of stage specific analyses are depicted in Table 2 (pT2, pT3, pT4, pTany, and / or lymph node disease) (Table 2) [11-13].

In the analysis of recurrence distribution, local and distant recurrence occurred in $31(8 \%)$ and $84(22 \%)$ patients in our study. There were no significant differences in the most common location and rate of recurrence from other large-scale studies $[14,15]$. There was only one patient with peritoneal carcinomatosis and 14 patients experienced recurrence of secondary urothelial carcinoma in the upper urinary tract (12 patients) and urethra (2 patients). The distribution of recurrence locations is shown in Table 3.

The margin positivity rate was $8 \%$ in our study which constituted 3\% for Ta/T1/T2 and 5\% for $\mathrm{T} 3 / \mathrm{T} 4$, respectively.

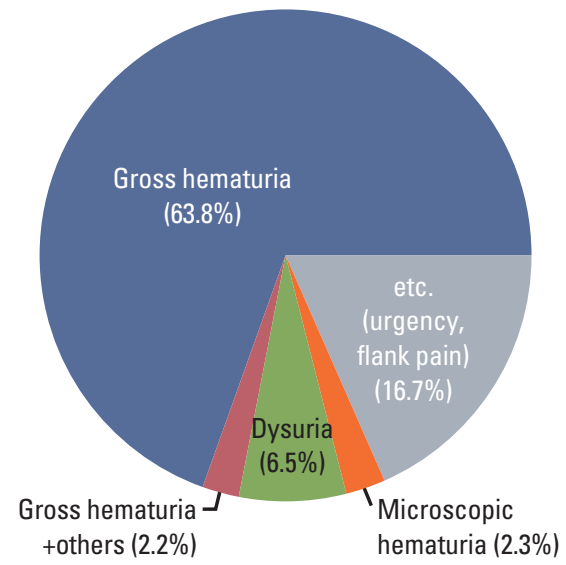

Fig. 1. Descriptions of the initial symptoms.

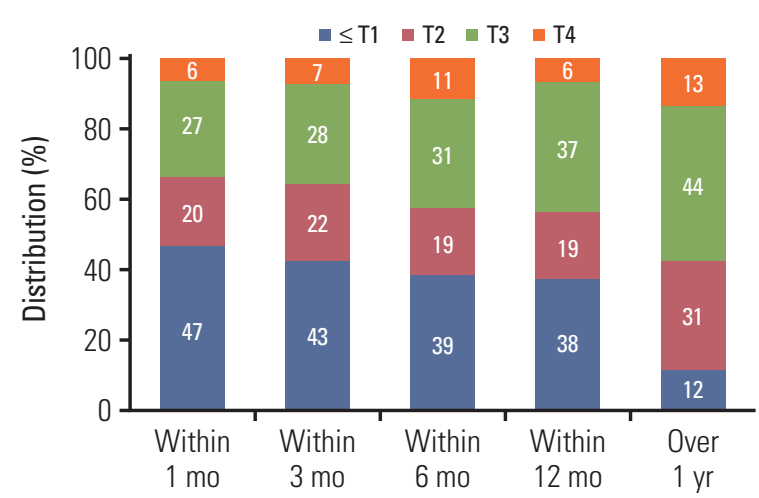

Fig. 2. Differences in pathologic T category according to the period for the urologic referral from symptom onset (T2 category and over proportion is dramatically increased after 1 year as $88 \%$ ).

Among the patients, 98 subjects $(26 \%)$ were found to have lymph node-positive disease. The histology of the tumors in the current series was predominantly urothelial carcinoma $(85 \%)$ followed by adenocarcinoma and squamous cell carcinoma.

\section{Present status of surgical methods of female RC}

Most of the operations were performed by the open method $(91.4 \%)$ and the proportion of laparoscopic or robotic surgeries was about $8.6 \%$. In trend, the composition of the number of surgeries did not vary much, with the number of open surgeries being slightly increased with the growth of robotic surgery, recently (Fig. 3A). In the analysis of the urinary diversion type, ileal conduits were performed in $80 \%$ of 
Table 2. Outcomes of female radical cystectomy by stage

\begin{tabular}{|c|c|c|c|}
\hline & 2-Year RFS (\%) & 5-Year RFS (\%) & 5-Year OS (\%) \\
\hline \multicolumn{4}{|l|}{ Reference/Cystectomy series } \\
\hline Stein et al. (2001) [11] & - & 68 & 66 \\
\hline Madersbacher et al. (2003) [12] & - & 62 & 59 \\
\hline Hautmann et al. (2006) [13] & - & 66 & 58 \\
\hline \multicolumn{4}{|l|}{ Current study } \\
\hline Overall & 72 & 57 & 61 \\
\hline pT2N0 & 70 & 52 & 60 \\
\hline \multicolumn{4}{|l|}{ pT3 or higher } \\
\hline pT3N0 & 62 & 49 & 56 \\
\hline pT4N0 & 49 & 42 & 45 \\
\hline pTanyN1-2 & 48 & 35 & 38 \\
\hline $\mathrm{p}$-value ${ }^{\mathrm{a})}$ & & 0.113 & 0.033 \\
\hline
\end{tabular}

RFS, recurrence-free survival; OS, overall survival. a)Log-rank test.

Table 3. Distribution of recurrence locations and incidences among female patients underwent radical cystectomy

\begin{tabular}{|c|c|}
\hline $\begin{array}{l}\text { Variable, frequency of } \\
\text { recurrence by site }\end{array}$ & $\begin{array}{l}\text { No. }(\%) \\
(\mathrm{n}=384)\end{array}$ \\
\hline Local recurrence & $31(8.0)$ \\
\hline Cystectomy bed & $13(3.3)$ \\
\hline PLND template & $18(4.7)$ \\
\hline Distant recurrence & $84(21.9)$ \\
\hline Lung & $24(6.3)$ \\
\hline Liver & $14(3.6)$ \\
\hline Bone & $25(6.5)$ \\
\hline Extrapelvic lymph node & $12(3.1)$ \\
\hline Peritoneal carcinomatosis & $1(0.3)$ \\
\hline Others (brain, adrenal, pancreas, bowel) & $8(2.1)$ \\
\hline Secondary urothelial carcinoma & $14(3.6)$ \\
\hline Upper urinary tract & $12(3.1)$ \\
\hline Urethra & $2(0.5)$ \\
\hline
\end{tabular}

PLND, pelvic lymph node dissection.

patients; ONB diversions were performed in $16 \%$ of patients, and continent cutaneous diversions were performed in 3\% of patients. In the recent 5 years, the increasing tendency of ONB reconstruction was shown (Fig. 3B). On surgical range, 51 patients (13\%) underwent organ sparing RC while 318 $(83 \%)$ patients received anterior pelvic exenteration. However, the number of patients who underwent organ-sparing $\mathrm{RC}$ had increased recently in the trend analysis (Fig. 3C).

\section{Complication rate}

The total complication rate was $47 \%$ and $70 \%$ of complications occurred within 30 days (127 patients) of surgery. The incidence of major and minor complications were 16\% (62 patients) and 31\% (119 patients), respectively. The most common complication categories were infectious $(13 \%$; most common $[\mathrm{m} / \mathrm{c}]$ urinary tract infection) wound $(9 \% ; \mathrm{m} / \mathrm{c}$ dehiscence), gastrointestinal (8\%; $\mathrm{m} / \mathrm{c}$ ileus), as shown in Table 4 . When only high-grade complications were considered, wound problems and genitourinary complications $(8 \%$, $\mathrm{m} / \mathrm{c}$ ureteral leakage/stricture) were the most prominent in all categories.

\section{Discussion}

It is known that women present with more advanced disease and a greater proportion die of the bladder cancer [16]. Kluth et al. [5] found a link between female gender and an increased risk of mortality following RC. In large cohort of reference cystectomy series (Table 2), overall 5 year RFS and OS were reported at about $62 \%-68 \%$ and $58 \%-66 \%$, respectively. Compared with these studies, our study showed worse 5 year RFS at $57 \%$ while the 5 year OS of $61 \%$ did not show a significant difference. In other studies on female RC (Table 5) $[2,17-20]$, OS and RFS were generally lower than those of reference studies, which were consistent with our study.

It is insufficient to explain the worse oncologic outcomes in females by epidemiologic factors. In our study, only $5 \%$ of females were smokers $(5.2 \%-7.9 \%$ of women vs. $39.4 \%-66.3 \%$ 

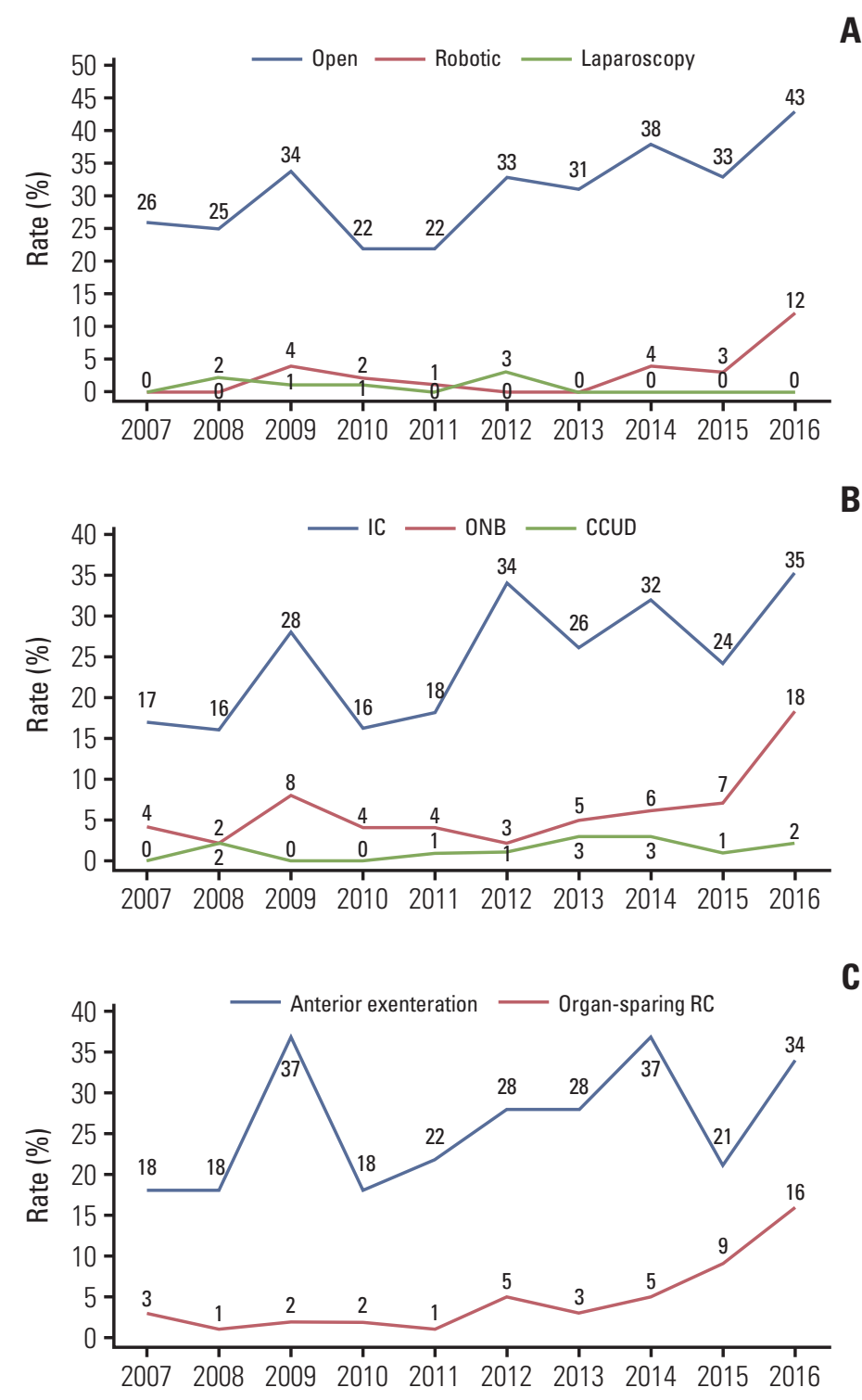

Fig. 3. Changes in the rates of each surgical technique of female radical cystectomy during 10 years. (A) Open/laparoscopy/ robotic. (B) Ileal conduit (IC)/ orthotopic neobladder (ONB)/ continent cutaneous urinary diversion (CCUD). (C) Anterior exenteration/organ sparing radical cystectomy $(\mathrm{RC})$.

of men for the last 20 years, data from Statistics Korea [21]) and even after combination with $2 \%$ of radiated patients, $93 \%$ of the cohorts had no exposure to any risk factors. In addition, despite the argument that perioperative factors could also play a role (women have longer operative times, more blood loss, and greater risk of complications than men) [22], the evidence is insufficient as well as inconsistent with the results of our study.

While some studies reported that men and women might metabolize carcinogens differently [23,24], it is quite possible that tumor biology, anatomic factors as well as delays in diagnosis may eventually answer this puzzling trend. One notable finding of our results is about urological referral pattern. In previous study, when a woman was referred, the time to referral was universally longer [25]. The most common symptom of bladder cancer is known to be either microscopic or macroscopic hematuria, which occurred in $66 \%$ of our cohort. Johnson et al. [7] reported that the adjusted hazard ratio of male referral to the urologist was 1.65 (95\% confidence interval, 1.31 to 2.08) compared with female referral 
Table 4. Summary of the common complications experienced

\begin{tabular}{|cc|}
\hline & No. $(\%)(\mathbf{n = 3 8 4})$ \\
\hline Total complication rate & $181(47.1)$ \\
\hline Within 30 days & $127(33.0)$ \\
\hline Within 90 days & $39(10.1)$ \\
\hline Over 90 days & $15(4.0)$ \\
\hline Major complication rate (Clavien grade 3-5) & $62(16.1)$ \\
\hline Minor complication rate (Clavien grade 1-2) & $119(31.0)$ \\
\hline Complication ${ }^{\text {a) }}$ & 181 \\
\hline Infectious (UTI and FUO) & $51(13.2)$ \\
\hline Wound (dehiscence and infection) & $36(9.3)$ \\
\hline GI (ileus and diarrhea) & $31(8.0)$ \\
\hline GU (ureteral leakage/ stricture and & $29(7.6)$ \\
parastomal hernia & \\
Bleeding (transfusion and NA) & $21(5.5)$ \\
\hline Cardiac (arrhythmia and NA) & $2(0.6)$ \\
\hline Etc. (DVT, lymphocele, pneumonia, hematoma) & $11(2.9)$ \\
\hline
\end{tabular}

UTI, urinary tract infection; FUO; fever of unknown origin; GI, gastrointestinal; GU, genitourinary; NA, not available; DVT, deep vein thrombosis; $\mathrm{m} / \mathrm{c}$, most common. a) $\mathrm{m} / \mathrm{c}$ and $2 \mathrm{nd} \mathrm{m} / \mathrm{c}$.

[7]. Because bladder cancer is less common in women, medical doctors may be less prone to consider this diagnosis at the woman's first visit. In addition, the higher frequency of urinary tract infections (UTI) among women or postmenopausal bleeding may lead to less extensive investigation thus delaying primary treatment. Although UTI is most common among women $<40$ years old, older women with gross hematuria might still undergo a limited evaluation due to the presumptive diagnoses of UTI. In our study, more than $36 \%$ of patients had a urologic referral after 3 months of symptom onset and 20\% even after 6 months. Previously, several studies documented poorer survival when the interval between cancer diagnosis and definitive treatment prolonged [26,27]. While there is not much difference in T2 or lower stage distribution (generally $60 \%$ ) in patients who visited within 1 year, T2 or higher portion increased significantly after 1 year which may have affected low RFS of our cohorts.

The anatomical differences between men and women are also important considerations. Male bladders have a thicker detrusor probably because of the need to void at higher intravesical pressures to overcome outflow resistance caused by the hyperplastic prostate gland. The thicker muscle may delay extravesical extension, and perhaps retard the development of metastases. Another anatomic difference that may affect disease progression is that the replacement of periurethral tissue in men by the prostate gland and its capsule may block the angiolymphatic extension of the tumor that is seen in women [28]. Also, differences in hormones have been discussed as possible causes of bladder cancer biology. The cell line of urothelial carcinoma is known to express both androgens and estrogens. The normal female urothelium expresses a higher density of estrogen receptors in the bladder trigone and posterior bladder neck than in men. In addition, this site and the roof of the vagina share an embryonic origin which is the most common site for invasion [29].

The present study details the contemporary trends regarding the distribution of urinary diversion among female patients undergoing RC for bladder cancer. Although a minority of patients received a continent diversion overall $(16 \%$ with ONB), a key finding in this study suggests that its use is indeed gradually increasing. For patients who are considering $\mathrm{RC}$, the choice of urinary diversion should be largely based on the feasibility of performing the operation safely and the ability to provide long-term care according to each patient's overall health and preference. After the 1980s, ONB has been performed for selected patients with improved knowledge of female pelvic anatomy. Also urethral recur-

Table 5. Survival analysis in a several series of female radical cystectomy

\begin{tabular}{|c|c|c|c|c|c|c|c|}
\hline Study & Study design & $\begin{array}{l}\text { Series } \\
\text { size }\end{array}$ & $\begin{array}{l}\text { Urinary } \\
\text { diversion }\end{array}$ & $\begin{array}{c}\text { Mean follow-up } \\
\text { period (mo) }\end{array}$ & $\begin{array}{c}\text { Organ } \\
\text { sparing }(\%)\end{array}$ & $\begin{array}{l}\text { 5-Year } \\
\text { OS (\%) }\end{array}$ & $\begin{array}{c}\text { 5-Year } \\
\text { RFS (\%) }\end{array}$ \\
\hline Granberg et al. (2008) [17] & Retrospective & 53 & ONB & 29.2 & 17 & 83 & 85 \\
\hline Ali-El-Dein (2009) [18] & Retrospective & 180 & ONB & 57 & - & - & 66 \\
\hline Stein et al. (2009) [19] & Retrospective & 120 & ONB & 102 & - & 58 & 62 \\
\hline Large et al. (2010) [20] & Retrospective & 92 & ONB (47), IC (45) & $34 / 24$ & - & $65 / 58$ & - \\
\hline Messer et al. (2014) [2] & Observational study & 890 & ONB, IC, CCUD & 31 & - & 52 & 69 \\
\hline Current study & Retrospective & 384 & ONB, IC, CCUD & 35 & 13 & 61 & 57 \\
\hline
\end{tabular}

OS, overall survival; RFS, recurrence-free survival; ONB, orthotopic neobladder; IC, ileal conduit; CCUD, continuous continent urinary diversion. 
rence is reported to have a low rate $(\leq 2 \%)$ in women [30].

Another trend identified in our study is the low rate of organ sparing cystectomy at about $13 \%$ and significant growth in the recent 5 years. This is thought to be a result of increased understanding of the anatomy, development of the surgical technique, and increased interest in the functional outcome. In fact, uterine preservation in some selected ONB patients helps prevent chronic retention (hypercontinence resulting from kinking of the ONB-urethral junction) by providing adequate back support. There is also a psychologic advantage to be gained by preserving the genital organs especially in the relatively young age groups. Therefore, organ preserving trials would be weighed for the preserva- tion of the uninvolved internal genital organs in selected women during RC.

While it is informative to assess the general characteristics of female RC it is essential to acknowledge the limitations of our study; first, the retrospective methodology and possible selection bias, and that our study was conducted on women and did not compare with male patients; therefore, comparison with a reference large cystectomy series is necessary.

\section{Conflicts of Interest}

Conflict of interest relevant to this article was not reported.

\section{References}

1. Cheng L, Weaver AL, Leibovich BC, Ramnani DM, Neumann RM, Scherer BG, et al. Predicting the survival of bladder carcinoma patients treated with radical cystectomy. Cancer. 2000;88:2326-32.

2. Messer JC, Shariat SF, Dinney CP, Novara G, Fradet Y, Kassouf $W$, et al. Female gender is associated with a worse survival after radical cystectomy for urothelial carcinoma of the bladder: a competing risk analysis. Urology. 2014;83:863-7.

3. Fajkovic H, Halpern JA, Cha EK, Bahadori A, Chromecki TF, Karakiewicz PI, et al. Impact of gender on bladder cancer incidence, staging, and prognosis. World J Urol. 2011;29:45763.

4. Herkommer K, Hofer C, Gschwend JE, Kron M, Treiber U. Gender and body mass index as risk factors for bladder perforation during primary transurethral resection of bladder tumors. J Urol. 2012;187:1566-70.

5. Kluth LA, Fajkovic H, Xylinas E, Crivelli JJ, Passoni N, Roupret $\mathrm{M}$, et al. Female gender is associated with higher risk of disease recurrence in patients with primary T1 high-grade urothelial carcinoma of the bladder. World J Urol. 2013;31: 1029-36.

6. van der Poel HG, Boon ME, vand er Meulen EA, WijsmanGrootendorst A. The reproducibility of cytomorphometrical grading of bladder tumours. Virchows Arch A Pathol Anat Histopathol. 1990;416:521-5.

7. Johnson EK, Daignault S, Zhang Y, Lee CT. Patterns of hematuria referral to urologists: does a gender disparity exist? Urology. 2008;72:498-502.

8. Bhatta Dhar N, Kessler TM, Mills RD, Burkhard F, Studer UE. Nerve-sparing radical cystectomy and orthotopic bladder replacement in female patients. Eur Urol. 2007;52:1006-14.

9. Ali-El-Dein B, Mosbah A, Osman Y, El-Tabey N, Abdel-Latif M, Eraky I, et al. Preservation of the internal genital organs during radical cystectomy in selected women with bladder cancer: a report on 15 cases with long term follow-up. Eur J
Surg Oncol. 2013;39:358-64.

10. Gakis G, Efstathiou J, Lerner SP, Cookson MS, Keegan KA, Guru KA, et al. ICUD-EAU International Consultation on Bladder Cancer 2012: Radical cystectomy and bladder preservation for muscle-invasive urothelial carcinoma of the bladder. Eur Urol. 2013;63:45-57.

11. Stein JP, Lieskovsky G, Cote R, Groshen S, Feng AC, Boyd S, et al. Radical cystectomy in the treatment of invasive bladder cancer: long-term results in 1,054 patients. J Clin Oncol. 2001;19:666-75.

12. Madersbacher S, Hochreiter W, Burkhard F, Thalmann GN, Danuser H, Markwalder R, et al. Radical cystectomy for bladder cancer today: a homogeneous series without neoadjuvant therapy. J Clin Oncol. 2003;21:690-6.

13. Hautmann RE, Gschwend JE, de Petriconi RC, Kron M, Volkmer BG. Cystectomy for transitional cell carcinoma of the bladder: results of a surgery only series in the neobladder era. J Urol. 2006;176:486-92.

14. Herr HW, Faulkner JR, Grossman HB, Natale RB, deVere White R, Sarosdy MF, et al. Surgical factors influence bladder cancer outcomes: a cooperative group report. J Clin Oncol. 2004;22:2781-9.

15. Nguyen DP, Al Hussein Al Awamlh B, Wu X, O'Malley P, Inoyatov IM, Ayangbesan A, et al. Recurrence patterns after open and robot-assisted radical cystectomy for bladder cancer. Eur Urol. 2015;68:399-405.

16. Mungan NA, Aben KK, Schoenberg MP, Visser O, Coebergh JW, Witjes JA, et al. Gender differences in stage-adjusted bladder cancer survival. Urology. 2000;55:876-80.

17. Granberg CF, Boorjian SA, Crispen PL, Tollefson MK, Farmer SA, Frank I, et al. Functional and oncological outcomes after orthotopic neobladder reconstruction in women. BJU Int. 2008;102:1551-5.

18. Ali-El-Dein B. Oncological outcome after radical cystectomy and orthotopic bladder substitution in women. Eur J Surg 
Oncol. 2009;35:320-5.

19. Stein JP, Penson DF, Lee C, Cai J, Miranda G, Skinner DG. Long-term oncological outcomes in women undergoing radical cystectomy and orthotopic diversion for bladder cancer. J Urol. 2009;181:2052-8.

20. Large MC, Katz MH, Shikanov S, Eggener SE, Steinberg GD. Orthotopic neobladder versus Indiana pouch in women: a comparison of health related quality of life outcomes. J Urol. 2010;183:201-6.

21. Lee ES, Seo HG, Fong GT, Yan M, Driezen P. Awareness of Korean adults smokers about national smoking cessation program in Korea: findings from the 2016 International Tobacco Control Policy Evaluation Survey_Korea. J Korean Soc Res Nicotine Tob. 2018;9 Suppl 1:S22-30.

22. Kluth LA, Rieken M, Xylinas E, Kent M, Rink M, Roupret M, et al. Gender-specific differences in clinicopathologic outcomes following radical cystectomy: an international multiinstitutional study of more than 8000 patients. Eur Urol. 2014;66:913-9.

23. Brauers A, Jakse G. Epidemiology and biology of human urinary bladder cancer. J Cancer Res Clin Oncol. 2000;126:575-83.

24. Lee R, Droller MJ. The natural history of bladder cancer.
Implications for therapy. Urol Clin North Am. 2000;27:1-13.

25. Hollenbeck BK, Dunn RL, Ye Z, Hollingsworth JM, Skolarus TA, Kim SP, et al. Delays in diagnosis and bladder cancer mortality. Cancer. 2010;116:5235-42.

26. Mommsen S, Aagaard J, Sell A. Presenting symptoms, treatment delay and survival in bladder cancer. Scand J Urol Nephrol. 1983;17:163-7.

27. Mansson A, Anderson H, Colleen S. Time lag to diagnosis of bladder cancer: influence of psychosocial parameters and level of health-care provision. Scand J Urol Nephrol. 1993;27:363-9.

28. Mungan NA, Kiemeney LA, van Dijck JA, van der Poel HG, Witjes JA. Gender differences in stage distribution of bladder cancer. Urology. 2000;55:368-71.

29. Saez S, Martin PM. Evidence of estrogen receptors in the trigone area of human urinary bladder. J Steroid Biochem. 1981;15:317-20.

30. Stein JP, Cote RJ, Freeman JA, Esrig D, Elmajian DA, Groshen $\mathrm{S}$, et al. Indications for lower urinary tract reconstruction in women after cystectomy for bladder cancer: a pathological review of female cystectomy specimens. J Urol. 1995;154:132933. 